\title{
Comparative EST transcript profiling of peach fruits under different post-harvest conditions reveals candidate genes associated with peach fruit quality
}

Paula Vizoso 1,3 , Lee A Meisel*1,3, Andrés Tittarelli2,3, Mariano Latorre ${ }^{2,3}$, Juan Saba ${ }^{3}$, Rodrigo Caroca1,3, Jonathan Maldonado ${ }^{2,3}$, Veronica Cambiazo 4,5, Reinaldo Campos-Vargas 1,3,6, Mauricio Gonzalez ${ }^{4}$, Ariel Orellana ${ }^{1,3}$ and Herman Silva*2,3

\begin{abstract}
Address: ${ }^{1}$ Centro de Biotecnología Vegetal, Universidad Andrés Bello, Santiago, Chile, ${ }^{2}$ Plant Functional Genomics \& Bioinformatics Lab, Universidad Andres Bello, Santiago, Chile, ${ }^{3}$ Millennium Nucleus in Plant Cell Biotechnology (MN-PCB), Santiago, Chile, ${ }^{4}$ Laboratorio de Bioinformática y Expresión Génica, INTA-Universidad de Chile, Santiago, Chile, ${ }^{5}$ Millennium Nucleus Center for Genomics of the Cell (CGC), Santiago, Chile and 'Institute of Agricultural Research (INIA-La Platina), Santiago, Chile

Email: Paula Vizoso - paula.vizoso@gmail.com; Lee A Meisel* - Imeisel@gmail.com; Andrés Tittarelli - tittarelli@gmail.com; Mariano Latorre - marianolatorre@gmail.com; Juan Saba - sabapc@yahoo.com; Rodrigo Caroca - rodrigocaroca@gmail.com; Jonathan Maldonado - jomaldon@gmail.com; Veronica Cambiazo - vcambiaz@inta.d; Reinaldo Campos-Vargas - rcampos@inia.cl; Mauricio Gonzalez - mgonzale@inta.cl; Ariel Orellana - aorellana@unab.cl; Herman Silva* - herman.silva@gmail.com

* Corresponding authors
\end{abstract}

Published: 10 September 2009

BMC Genomics 2009, 10:423 doi:10.1186/147|-2/64-10-423
Received: 19 December 2008

Accepted: 10 September 2009

This article is available from: http://www.biomedcentral.com/I47I-2/64/I0/423

(c) 2009 Vizoso et al; licensee BioMed Central Ltd.

This is an Open Access article distributed under the terms of the Creative Commons Attribution License (http://creativecommons.org/licenses/by/2.0), which permits unrestricted use, distribution, and reproduction in any medium, provided the original work is properly cited.

\begin{abstract}
Background: Cold storage is used to inhibit peach fruit ripening during shipment to distant markets. However, this cold storage can negatively affect the quality of the fruit when it is ripened, resulting in disorders such as wooliness, browning or leathering. In order to understand the individual and combined biological effects that factors such as cold storage and ripening have on the fruit and fruit quality, we have taken a comparative EST transcript profiling approach to identify genes that are differentially expressed in response to these factors.
\end{abstract}

Results: We sequenced 50,625 Expressed Sequence Tags (ESTs) from peach mesocarp (Prunus persica O'Henry variety) stored at four different postharvest conditions. A total of I0,830 Unigenes (4,169 contigs and 6,66I singletons) were formed by assembling these ESTs. Additionally, a collection of 614 full-length and I,I09 putative full-length cDNA clones within flanking loxP recombination sites was created.

Statistically analyzing the EST population, we have identified genes that are differentially expressed during ripening, in response to cold storage or the combined effects of cold storage and ripening. Pair-wise comparisons revealed 197 contigs with at least one significant difference in transcript abundance between at least two conditions. Gene expression profile analyses revealed that the contigs may be classified into 13 different clusters of gene expression patterns. These clusters include groups of contigs that increase or decrease transcript abundance during ripening, in response to cold or ripening plus cold. 


\begin{abstract}
Conclusion: These analyses have enabled us to statistically identify novel genes and gene clusters that are differentially expressed in response to post-harvest factors such as long-term cold storage, ripening or a combination of these two factors. These differentially expressed genes reveal the complex biological processes that are associated with these factors, as well as a large number of putative gene families that may participate differentially in these processes. In particular, these analyzes suggest that woolly fruits lack the increased boost of metabolic processes necessary for ripening. Additionally, these results suggest that the mitochondria and plastids play a major role in these processes. The EST sequences and full-length cDNA clones developed in this work, combined with the large population of differentially expressed genes may serve as useful tools and markers that will enable the scientific community to better define the molecular processes that affect fruit quality in response to post-harvest conditions and the organelles that participate in these processes.
\end{abstract}

\section{Background}

In order to improve fruit quality, it is important not only to take into account the quality of the fruit when it is harvested from the tree, but also post-harvest quality. After harvesting, fruits are packed and shipped to local and foreign markets. They remain on the shelf at supermarkets and/or farmers markets until the consumer purchases the fruits and finally consumes it. For this reason, the effects that shipping and storage have on fruit quality are very important. One of the most common methods to increase the post-harvest life of fruits is to store them in refrigeration, so that ripening is inhibited. However, prolonged cold storage of fruits such as peaches and nectarines can trigger a physiological disorder known as chilling injury or internal breakdown, which negatively affects fruit quality [1-3].

One of the most important problems associated with chilling injury is mealiness/woolliness. After prolonged cold storage, fruits produce a woolly phenotype when ripened. Woolly fruits lack juice and have a mealy texture, making them inedible and undesirable to consumers. This, in turn, leads to large economical losses for the fruit industry [4-6]. Chilling injuries such as wooliness are especially problematic for major counter-season fruit exporters such as Chile [4,7]. A better understanding of the molecular and cellular processes that lead to ripening, as well as woolliness, may provide future strategies to increase the shelf-life while minimizing the negative effects of cold-storage on fruit quality [8].

Wooliness occurs when fruits, stored between $0-8^{\circ} \mathrm{C}$ for prolonged periods of time, are transferred to conditions in which fruit ripening may occur. Under normal conditions, peach fruit ripening has been associated with changes in the expression of genes that code for cell wall degradation enzymes and the subsequent changes in enzymatic activity [9-11]. Various studies have provided correlative evidence that wooliness is associated with an imbalance between the activity of the cell wall-degrading enzymes, polygalacturonase (PG) and pectin methylesterase (PME) [9-11]. Additionally, by using macroarray analyses to compare the transcripts present in juicy fruits with those from wooliness, we have previously identified a number of genes that are differentially expressed in these fruits [12]. Ogundiwin et al, have also identified genes that are differentially expressed between juicy and woolly fruits using microarray analyses [13].

However, the susceptibility of peaches and nectarines to become woolly after prolonged cold-storage has been associated with particular peach and nectarine cultivars $[3,14,15]$, as well as seasonal variation [3]. Cultivar specificity and seasonal variation suggest that multiple factors participate in developing a woolly phenotype in peach fruits $[1,3]$. Therefore, it is important to analyze not only the final end product (woolly fruits), but also the multiple factors that may be causing wooliness.

To identify the molecular mechanisms associated with developing wooliness, we have taken a global approach towards identifying genes that are differentially expressed in response to factors such as cold, ripening, or the combined effects of these two factors (cold + ripening), the latter of which results in the woolly peach phenotype.

We sequenced and statistically analyzed the abundance of Expressed Sequence Tags (ESTs) from peaches at four different post-harvest conditions, mimicking the stages of cold storage for fruit exportation. This statistical analysis has enabled us to identify target genes whose expression is affected by post-harvest factors such as long-term cold storage, ripening or the combined effects of these two factors. These analyses also reveal the different biological processes that are occurring under each post-harvest condition and the differences between these conditions. Additionally, we have generated a collection of full-length cDNA clones flanked by two loxp sites which may be useful in confirming the functionality of these gene products and the future annotation of the peach genome. 


\section{Results and Discussion}

In order to identify genes that are differentially expressed in response to factors such as long-term cold storage (C), genes that are differentially expressed during ripening $(\mathrm{R})$, as well as the combined effects of these two factors (longterm cold storage and ripening), a $2 \times 2$ factorial design was used to generate four cDNA libraries that can be used for statistical comparative analyses [16].

These libraries represent the mesocarp tissue of O'Henry peaches (Prunus persica) under the following four distinct post-harvest conditions:

$$
\begin{aligned}
& \mathrm{E} 1=\text { non-ripe; no long-term cold storage }=\mathrm{R}^{-}, \mathrm{C}^{-} \\
& \mathrm{E} 2=\text { ripe; no long-term cold storage }=\mathrm{R}^{+}, \mathrm{C}^{-} \\
& \mathrm{E} 3=\text { non-ripe; long-term cold storage }=\mathrm{R}^{-}, \mathrm{C}^{+} \\
& \mathrm{E} 4=\text { ripe: long-term cold storage }=\mathrm{R}^{+}, \mathrm{C}^{+}
\end{aligned}
$$

The maturity and physiological parameters of the fruits used to create these libraries are reported in Campos-Vargas et al [3]. These maturity and physiological parameters include firmness, percentage of total soluble solids, respiration rate and ethylene production [3].

$5^{\prime}$ end sequencing of clones from these libraries resulted in a total of 50,625 EST sequences. Assessment of these EST sequences revealed that a total of 41,519 ESTs are "good quality" sequences (average Phred Q>20 between bases 100 and 300 for each EST). Relatively equal num- bers of "good quality" ESTs from each of the four postharvest conditions were used for further analyses (Table 1 , Figure 1, Additional File 1, Table S1).

As of May 2009, there were 79,023 Prunus persica EST sequences in NCBI, of which 32,497 ESTs correspond to sequences reported in this manuscript, but were publicly release to NCBI in 2006 (accession numbers: DY633390DY654328, DW347789-DW359346). These 32,497 prerelease EST sequences also make up almost half of the sequences available in the ESTree database $(75,404 \mathrm{ESTs})$ $[17,18]$. In addition to the sequences we have release previously, we are releasing an additional 9,022 EST sequences with the publication of this manuscript. This is a total of 41,519 ESTs which are being reported for the first time in this manuscript.

Assembling these 41,519 ESTs using CAP3 95/60 resulted in the identification of 10,830 Unigenes $(4,169$ contigs and 6,661 singletons). EST distribution in the contigs is presented in Additional File 1, Table S2. BLASTn and BLASTx analyses revealed that $98.9 \%$ of the contigs shared homology to sequences in public databases, whereas the remaining 47 contigs and 656 singletons showed no significant homology to the sequences in the public databases. Interestingly, although there is a high level of homology between the consensus sequences of our Unigenes and the sequences in public databases, 3,786 of our Unigenes contain novel sequence information, not

\begin{tabular}{|c|c|c|c|c|c|}
\hline & \# of EST sequences & Average lengthb & $\begin{array}{r}\text { Maximum EST } \\
\text { length }^{\mathrm{b}}\end{array}$ & $\begin{array}{r}\text { Minimum EST } \\
\text { length }\end{array}$ & $\begin{array}{r}\text { Assigned GO } \\
\text { annotation }\end{array}$ \\
\hline $\begin{array}{l}\text { Total number of "good } \\
\text { quality"a ESTs }\end{array}$ & 45,809 & 834 & ND & ND & ND \\
\hline $\begin{array}{l}\text { ESTs without inverse } \\
\text { ligation and PolyT }\end{array}$ & 44,214 & 835 & ND & ND & 42,128 \\
\hline ESTs after trimmer & 41,519 & 584 & 895 & 100 & 41,519 \\
\hline ESTs in contigs & 34,858 & 589 & 895 & 100 & 34,858 \\
\hline ESTs in singletons & 6,661 & 556 & 871 & 101 & 6,661 \\
\hline Contigs & 4,169 & 861 & 3,082 & 109 & 4,169 \\
\hline Unigenes & 10,830 & 673 & 3,082 & 101 & 10,830 \\
\hline
\end{tabular}
present in public databases such as NCBI, ESTree, PlantTA, GDR and ChillPeach [13,17-21].

Table I: Prunus persica Unigene Set Statistics

a Average Phred Q>20 between bases 100 and 300)

b base pairs

c Assigned GO annotations were derived from the annotation protocol

ND: not determined 


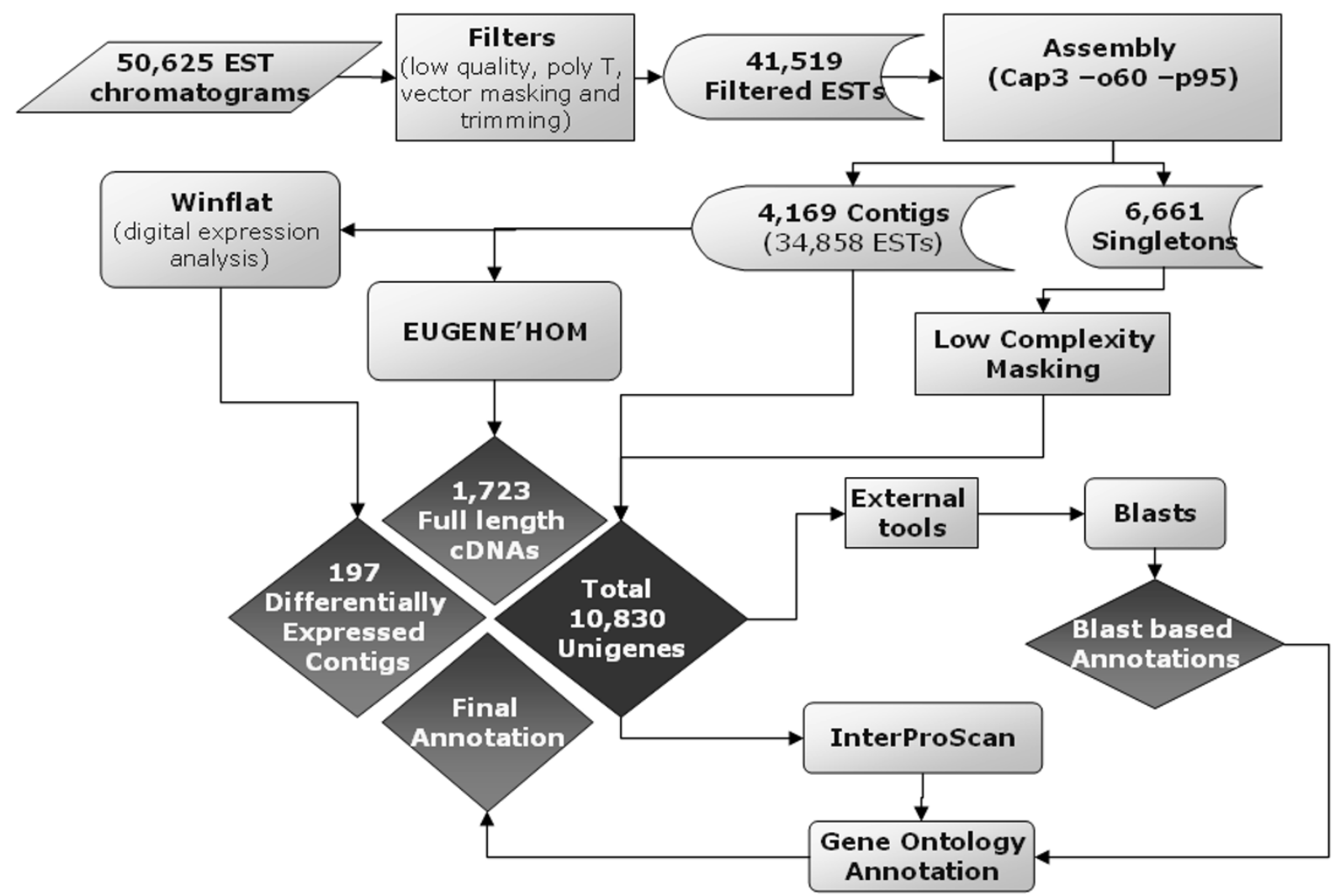

\section{Figure I}

Flowchart of the in silico EST analyses. Chromatograms represent 5'EST end-sequences from four cDNA libraries of fruits with different post harvest treatments. Sequences were filtered, resulting in 4I,519 ESTs that were used for assembling contigs. Assemblies generated 4,169 contigs and 6,66I singletons, resulting in a total of 10,830 Unigenes. The singletons were subsequently filtered for low complexity. The consensus sequence of each contig was further analyzed using EuGène'Hom to determine the number of full-length cDNAs. Using this analysis, I,723 full-length cDNAs were identified (6I4 full-length cDNAs and I, 109 putative full-length cDNAs). Additionally, the number of ESTs in each contig was analyzed statistically to determine if the gene (s) that represent these contig are differentially expressed under the conditions analyzed [27].

BLAST, Interproscan and BLAST2GO analyses were used to annotate the Unigenes and ESTs [22-26]. Gene Ontology (GO) annotations were assigned to the ESTs and contigs. Detailed information associated with the ESTs, contig consensus sequences and their associated annotations are available to browse or download at http://www.genom avegetal.cl/juice/EST[27].

The length of the contig consensus sequences ranged from 0.1 to $3.0 \mathrm{~kb}$, with an average length of $0.9 \mathrm{~kb}$ (Table 1 ). This large size detected in the consensus sequences suggests that some of these cDNA clones may be full-length. Analyses of the contig consensus sequences with EuGène'Hom [28] enabled us to identify the components of a full-length cDNA (5' UTR, ORF and 3' UTR). These analyses identified 614 full-length cDNAs, ranging in size from 0.4 to $2.7 \mathrm{~kb}$ (Table 2). Additionally, 1,109 contigs represent putative full-length cDNAs, in which the 5' UTR and ORF regions were detected. Since we performed 5'end sequencing on these putative full-length cDNAs clones, they should contain the 3' UTR. Further 3' sequencing of these clones will confirm the full-length clones.

A summary of the results from this EuGène'Hom analysis is presented in Table 2. The clones of these full-length cDNAs have been identified by correlating the ESTs that are at the 5 ' end of the consensus sequences with the clones that these ESTs represent. Correlations between the insert size of many of these clones and the size of the contig consensus sequence suggests that the EuGène'Hom predictions are accurate (data not shown). Since our cDNA libraries were made in Clontech's $\mathrm{pDNR}-1 \mathrm{r}$ vector, these full-length and putative full-length cDNAs have flanking loxP recombination sites on both sites of the cDNAs [29,30]. 
Table 2: Full-length cDNA sequences identified with EuGène'Hom.

\begin{tabular}{|c|c|c|c|c|c|}
\hline Category & Consensus Sequence Structure ${ }^{a}$ & Average Lengthb & Maximum Lengthb & Minimum Lengthb & \# Contigs \\
\hline 1 & 5' UTR - ORF - 3'UTR & 970 & 2,715 & 376 & 614 \\
\hline 2 & 5' UTR - ORF & 832 & 2,579 & 388 & 1,109 \\
\hline 3 & 5' UTR & 705 & 1,670 & 384 & 115 \\
\hline 4 & ORF - 3'UTR & 900 & 2,670 & 241 & 782 \\
\hline 5 & ORF & 834 & 3,082 & 149 & 1,117 \\
\hline 6 & 3'UTR & 709 & 1,334 & 109 & 220 \\
\hline \multirow[t]{2}{*}{7} & NAc $^{c}$ & 936 & 2,323 & 525 & 212 \\
\hline & Total & & & & 4,169 \\
\hline
\end{tabular}

a The structure of the contig consensus sequence were analyzed using EuGène'Hom [2I]. The results of this analysis were divided into 7 categories, I: Full-length (5' UTR - ORF - 3'UTR; 2: Putative Full-length (5' UTR - ORF); 3: only 5' UTR; 4: only ORF - 3'UTR; 5: only ORF; 6: only 3'UTR; 7: none of the previous mentioned structures.

$b$ base pairs

c NA: No identifiable structures

Differential expression of genes in each post-harvest stage To estimate the distribution of ESTs from individual contigs among four cDNA libraries, a two-dimensional hierarchical clustering using pair-wise average-linkage cluster analysis [31] was applied. To ensure that contigs made up of a low number of ESTs are not unrepresented in the cluster analyses, the number of ESTs in each library was normalized proportionally to the total number of ESTs in their corresponding contig. The hierarchical clustering of the normalized contigs (Additional File 1, Figure S1), revealed that the distribution of ESTs in E1 ( $\left.\mathrm{R}^{-}, \mathrm{C}^{-}\right)$and E3 $\left(\mathrm{R}^{-}, \mathrm{C}^{+}\right)$are more similar to each other when compared to E2 $\left(\mathrm{R}^{+}, \mathrm{C}^{-}\right)$or E4 $\left(\mathrm{R}^{+}, \mathrm{C}^{+}\right)$. Similarly, E2 $\left(\mathrm{R}^{+}, \mathrm{C}^{-}\right)$and E4 $\left(\mathrm{R}^{+}\right.$, $\left.\mathrm{C}^{+}\right)$are more similar to each other when compared to E1 $\left(\mathrm{R}^{-}, \mathrm{C}^{-}\right)$or E3 $\left(\mathrm{R}^{-}, \mathrm{C}^{+}\right)$.

Relative gene expression can be determined by statistically comparing the number of ESTs from a gene between different libraries or different genes in the same library [32]. Pair-wise comparisons of the number of ESTs from each post-harvest condition, revealed differentially expressed genes $(\mathrm{p}<0.01)$. Based on this statistical analysis, 197 contigs with at least one significant difference in gene expression were detected between the different post-harvest conditions. A total of 30 genes increase expression in ripe, juicy fruits $\left(\mathrm{E} 2: \mathrm{R}^{+}, \mathrm{C}^{-}\right)$when compared to non-ripe fruits (E1: $\mathrm{R}^{-}, \mathrm{C}^{-}$), whereas 39 genes are reduced (Additional File 2, Table S4). Long-term cold stored fruits (E3: $\left.\mathrm{R}^{-}, \mathrm{C}^{+}\right)$increases the expression of 56 genes and decreases the expression of 45 genes when compared to fruits that have not undergone this long-term storage (E1: $\mathrm{R}^{-}, \mathrm{C}^{-}$;
Additional File 2, Table S5). Fruits that are ripened following long-term cold storage and are woolly $\left(\mathrm{E} 4: \mathrm{R}^{+}, \mathrm{C}^{+}\right)$ have an increased expression of 36 genes and a decreased expression of 68 genes when compared to unripe fruits that have undergone long-term storage (E3: R-, $\mathrm{C}^{+}$; Additional File 2, Table S6). A total of 9 genes have a statistically significant increase in expression in woolly ripened long-term cold stored fruits $\left(\mathrm{E} 4: \mathrm{R}^{+}, \mathrm{C}^{+}\right)$when compared to juicy ripened fruits that have not been stored in the cold $\left(\mathrm{E} 2: \mathrm{R}^{+}, \mathrm{C}^{-}\right)$, whereas 8 genes are reduced (Additional File 2, Table S7).

This in silico analysis was validated by performing qPCR analyses on several of the contigs that showed differential gene expression levels based upon the pair-wise in silico analyses (Figure 2, Additional File 2 Tables S4-S7). Figure 2 reveals differential gene expression confirmed by performing QPCR analyses of the following contigs under the four post-harvest conditions: Wcor (contig30), dormancyassociated protein (DRM1; contig438), polygalacturonase (contig 1123), luminal binding protein 1 (BIP-1; contig2715), temperature-induced lipocalin (TIL) (contig 2980), and lipoxygenase (contig 3870) (Figure 2). This comparative analysis revealed that the in silico and qPCR assays yield similar results for these genes, under the conditions analyzed.

\section{Ripening related genes}

The pair-wise comparison of EST abundance of our contigs between two stages, revealed a significant increase in the transcript levels of 30 genes in these ripe fruits (E2: $\mathrm{R}^{+}$, 

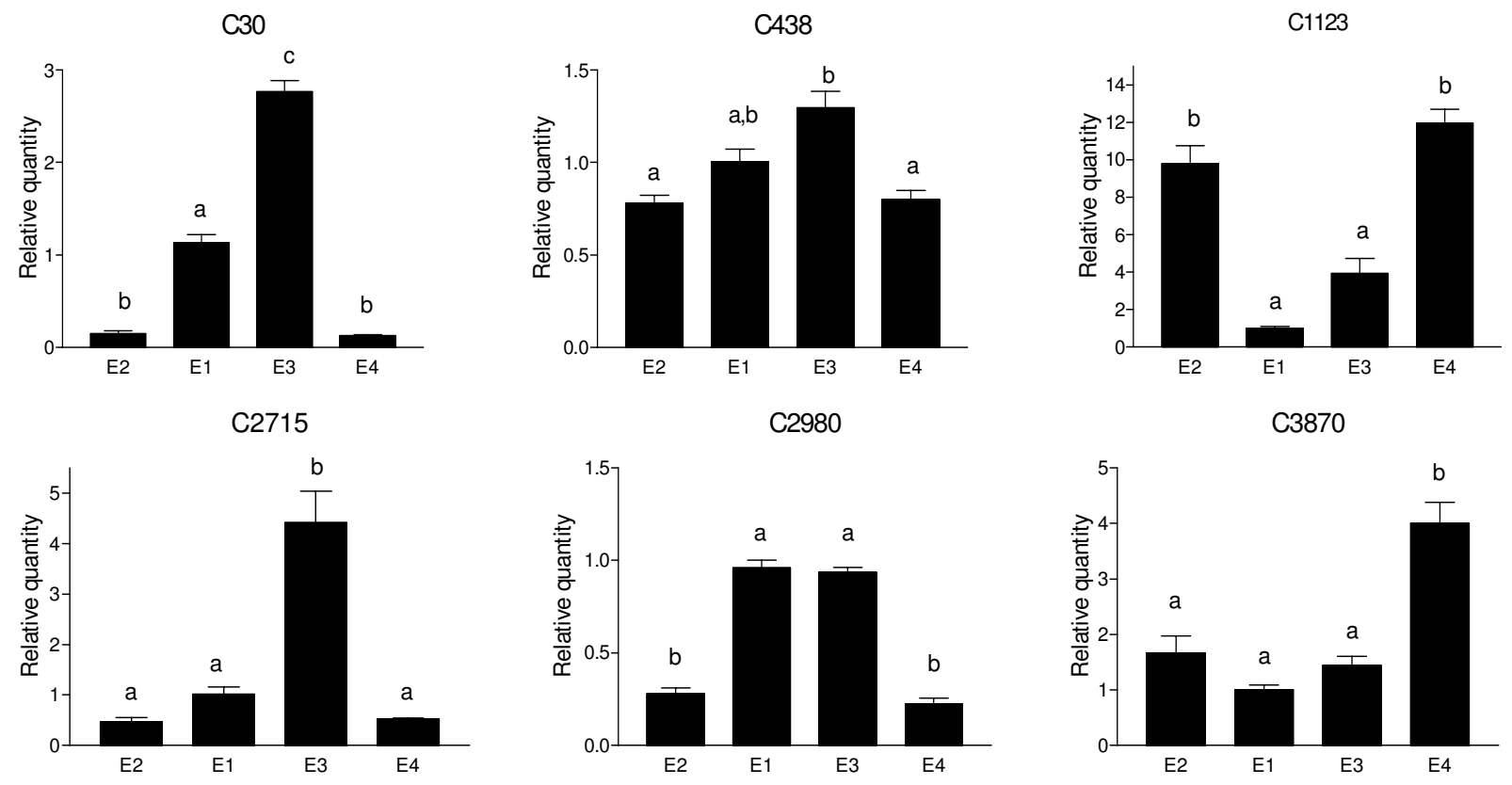

Figure 2

Relative quantity of transcript levels in response to long-term cold storage, ripening, as well as the combination of these two factors. The qPCR data was obtained by analyzing the transcript level of contigs $30,438,1$ I 23,27 I 5, 2980 and 3870) under four post-harvest conditions, normalized against a gene which did not demonstrate significant variations in transcript levels (Dehydrogenase/GMP reductase, contig 2766). Graphed qPCR data represents the mean transcript level of three or four individual fruits \pm the standard error. EI = non-ripe; no long-term cold storage = R-, C-; E2 = ripe; no long-term cold storage $=\mathrm{R}^{+}, \mathrm{C}-\mathrm{E3}=$ non-ripe; long-term cold storage $=\mathrm{R}^{-}, \mathrm{C}^{+} ; \mathrm{E} 4=$ ripe: long-term cold storage $=\mathrm{R}^{+}$, $\mathrm{C}^{+}$. contig30: Wcor; contig438: dormancy-associated protein (DRMI); contig I I23: polygalacturonase; contig27I5: luminal binding protein I (BIP-I); contig 2980: temperature-induced lipocalin (TIL) and contig 3870: lipoxygenase.

$\left.\mathrm{C}^{-}\right)$when compared to the unripe fruits (E1: R-, $\mathrm{C}^{-}$), and a reduction in the transcript levels of 39 genes (Additional File 2, Table S4). It is important to note that the fruits reported by Campos-Vargas et al [3] are the same fruits that were used for constructing our libraries. As reported by Campos-Vargas et al [3], ripe fruits were less firm than unripe fruits (7.9 N versus $72.5 \mathrm{~N}$, respectively), but had a higher respiration rate (110.8 versus $28.8 \mathrm{~mL} \mathrm{CO}_{2} \mathrm{~kg}^{1} \mathrm{~h}^{1}$, respectively) and ethylene production (4.7 versus $1.6 \mu \mathrm{L}$ $\left.\mathrm{C}_{2} \mathrm{H}_{4} \mathrm{~kg}^{1} \mathrm{~h}^{1}\right)[3,33-38]$.

The annotations of these differentially expressed transcripts reveal genes that participate in the physiological changes detected between ripe and unripe fruits. For example, 5 polygalacturonase transcripts (contigs1123, 1507, 1745, 3321, and 3904) are accumulated higher in ripe fruits than unripe fruits (Additional File 2, Table S4), which may lead to the changes in fruit firmness. These contigs share high identity (97-99\%) with the polygalacturonase that was identified in microarray analyses of ripening fruits $[11,39]$. These results are consistent with the increase of endopolygalacturonase enzymatic activity in ripened peach fruits which has been reported previously $[40,41]$.

In addition to the increased transcript accumulation of polygalacturonases, we detected a decreased expression of pectate lyase (contig 3683) and pectin methylesterase inhibitor genes (contigs 59 and 3598) (Additional File 2, Table S4). Trainotti et al [11] have detected increases in pectate lyase transcripts during the S4I phase of peach fruit ripening (climateric fruits that have not undergone softening, 115 days post-fertilization) and then decreases in the S4II phase (climateric fruits that have softened, 120-125 days post-fertilization). Our pair-wise comparisons of ESTs between ripe and unripe fruits detect a decrease in pectate lyase in ripe fruits when compared to unripe fruits (Additional File 2, Table S4). This decrease in pectate lyase gene expression as well as the reduction in firmness of the ripened fruits [3] suggests that our E2 stage is similar to the S4II stage described by Trainotti et al [11]. 
In addition to cell wall modifying enzymes, we have detected increased expression of genes associated with ethylene biosynthesis such as S-Adenosyl Methionine Synthetase (SAM Synthetase, contig 3949) and 1-Aminocyclopropane-1-Carboxylate Oxidase (ACC oxidase, contig 1901) (Additional File 2, Table S4). The increase in expression of this ACC oxidase (contig 1901) in ripe fruits has also been detected by Trainotti et al [39], whereas the SAM synthetase was not. The differential expression of these genes may also explain the increase in ethylene production detected in the ripe $\left(\mathrm{E} 2: \mathrm{R}^{+}, \mathrm{C}^{-}\right)$fruits.

As mentioned earlier, we have also detected an increased respiration in ripe fruits when compared to unripe fruits [3]. The pair-wise comparison reveals increased expression in several genes associated with glycolysis which may lead to this increase in respiration (Additional File 2, Table S4). These genes include Fructose-bisphosphate aldolase (contig 1358), glyceraldehyde 2-phosphate dehydrogenase (contig 1653) and pyruvate decarboxylase (contigs 1054 and 2749).

\section{Cold-storage related genes}

Changes in firmness and respiration rate were also seen when unripe fruits stored at $4^{\circ} \mathrm{C}\left(\mathrm{E} 3: \mathrm{R}-\mathrm{C}^{+}\right)$were compared to unripe fruits prior to storage (E1: $\mathrm{R}$, $\mathrm{C}-$; firmness: 43.2 versus $72.5 \mathrm{~N}$; Respiration rate: 94.3 versus $28.8 \mathrm{CO}_{2}$ $\operatorname{kg}^{1} \mathrm{~h}^{1}$, respectively) [3]. The pair-wise analyses reveal 56 genes that increase expression and 45 genes that decrease expression as a result of this long-term cold storage (Additional File 2, Table S5). Several of these genes are associated with cell wall organization and, therefore, may be associated with the changes detected in firmness. Genes that increase include: polygalacturonase inhibiting protein 1 (contig 2988), pectin methylesterase (contig 2877), basic endochitinase (contig 2131), and endopolygalacturonases (contigs 1507 and 1745). Genes that decrease include: expansin (contig 1200), invertases/pectin methylesterase inhibitors (contigs 59, 1945 and 3598), and pectate lyase (contig 3683). Among these cell wall associated contigs, only the basic endochitinase (contig 2131) has been reported previously to have altered expression in long-term cold stored fruits [13].

In addition to the altered expression of cell wall modifying proteins, we have also detected increased expression of glutathione peroxidase (contig 2514; Additional File 2, Table S5). Glutathione peroxidase is an oxidative stress responsive gene, which suggests that the fruits that have been stored for prolonged periods of time have an increase in oxidative stress, possibly associated with the increased respiration rates. Oxidative stress has been demonstrated in many species to be associated with chilling injury [42-45].
Among the genes differentially expressed between fruits that have undergone prolonged cold storage with those that have not, seven of these correspond to the genes that Ogundiwin et al [13] have also identified as having altered expression following cold storage (contigs 1546, 1693, 2131, 2311, 2495, 2957 and 2988). The remaining 94 contigs that are differentially expressed between unripe fruits stored at $4^{\circ} \mathrm{C}\left(\mathrm{E} 3: \mathrm{R}^{-}, \mathrm{C}^{+}\right)$and unripe fruits prior to storage $\left(\mathrm{E} 1: \mathrm{R}^{-}, \mathrm{C}^{-}\right)$are novel and may participate in the adaptation and/or stress responses associated with longterm cold storage of these fruits.

\section{Wooliness response genes}

When fruits that have been stored for long periods of time in cold storage $\left(\mathrm{E} 3: \mathrm{R}^{-}, \mathrm{C}^{+}\right)$are removed from this storage and ripened $\left(\mathrm{E} 4: \mathrm{R}^{+}, \mathrm{C}^{+}\right)$, there is a significant decrease in firmness (43.2 versus $6.8 \mathrm{~N}$, respectively), a significant increase in ethylene production (1.0 versus $18.1 \mu \mathrm{L}$ $\mathrm{C}_{2} \mathrm{H}_{4} \mathrm{~kg}^{1} \mathrm{~h}^{1}$, respectively) and the fruits have a woolly phenotype [3]. The pair-wise analyses reveal an increased expression of 36 genes and a decreased expression of 68 genes in fruits that are ripened following long-term cold storage and are woolly $\left(\mathrm{E} 4: \mathrm{R}^{+}, \mathrm{C}^{+}\right)$in comparison to unripe fruits that have undergone long-term storage but are unripe (E3: $\mathrm{R}^{-}, \mathrm{C}^{+}$; Additional File 2, Table S6). Additionally, these analyses reveal an increased expression of 9 genes and decreased expression of 8 genes when woolly fruits are compared to juicy fruits, $\left(\mathrm{E} 4: \mathrm{R}^{+}, \mathrm{C}^{+}\right.$and E2: $\mathrm{R}^{+}$, $\mathrm{C}^{-}$, respectively; Additional File 2, Table S7).

The changes in firmness and the wooliness phenotype have been reported previously to be correlated with modifications in the levels of cell wall modifying enzymes $[1,9,40,41,46-49]$. As mentioned earlier, our pair-wise analyses have identified five polygalacturonase transcripts with increased accumulation in ripe fruits when compared to unripe fruits (contigs 1123, 1507, 1745, 3321 and 3904; Additional File 2, Table S4-7). Of these five transcripts, two (contigs 1507 and 1745) have an increased accumulation following long-term cold storage. Ripening of the cold stored fruits produces an increased accumulation of four of these polygalacturonase transcripts (contigs 1507, 1745, 3321 and 3904). However, when comparing juicy fruits with woolly fruits, there is less accumulation of three of these transcripts (contigs 1123,1507 and 1745) in woolly fruits. These results suggest that in woolly peaches there are diverse polygalacturonase transcripts which are unable to accumulate to the levels normally present in ripe juicy fruits. These results are complementary to several studies that have linked polygalacturonase activity with wooliness [1,9-12,3941,46-50]. Interestingly, Peace et al [51] have also identified an endopolygalacturonase that co-localizes with a major QTL affecting both mealiness and bleeding. The 
large number of different polygalacturonase transcripts may be a result of alternative splicing or a recent gene duplication resulting in a highly conserved polygalacturonase gene family. The completion of the peach genome sequence will help to clarify whether these transcripts are a result of multiple genes or alternative splicing.

In addition to the changes in the accumulation of polygalacturonase transcripts, we have also identified a polygalacturonase inhibiting protein that has an inverse expression when compared to polygalacturonase in fruits that are ripened following a long-term cold storage and have a woolly phenotype. That is, there is a reduced expression of the polygalacturonase inhibiting protein in woolly fruits $\left(\mathrm{E} 4: \mathrm{R}^{+}, \mathrm{C}^{+}\right)$when compared to unripe fruits that have undergone long-term cold storage $\left(\mathrm{E} 3: \mathrm{R}, \mathrm{C}^{+}\right)$. This reduction in the expression of the polygalacturonase inhibiting protein may lead to an increase in polygalacturonase activity and subsequent reduction in the fruit firmness. A similar pattern of reduced expression in fruits that are ripened following a long-term cold storage is also seen for another cell wall modifying enzyme, endochitinase (contig 2131).

A decrease in pectate lyase expression (contig 3683) was detected when comparing ripen fruits E2 $\left(\mathrm{R}^{+}, \mathrm{C}^{-}\right)$with unripe fruits E1 ( $\left.\mathrm{R}^{-}, \mathrm{C}^{-}\right)$. However, a decrease in expression of this contig was also detected in fruits stored for prolonged periods of time in the cold (E3: $\mathrm{R}^{-}, \mathrm{C}^{+}$versus E1: $\mathrm{R}^{-}$ , $\left.\mathrm{C}^{-}\right)$, suggesting that this decrease may be similar to the decrease detected by Trainotti et al [11] in the S4II stage (climateric fruits that have softened, 120-125 days postfertilization). Interestingly, the expression levels of this pectate lyase increased in woolly ripened long-term cold stored fruits $\left(\mathrm{E} 4: \mathrm{R}^{+}, \mathrm{C}^{+}\right)$when compared to long-term cold stored fruits (E3: $\left.\mathrm{R}^{-}, \mathrm{C}^{+}\right)$. We have previously reported a decreased transcript level of pectate lyase when woolly fruits were compared to juicy fruits by macroarray analyses [12]. One explanation for this is that the cold-storage may have reduced the pectate lyase transcript to a point that despite the increased expression of pectate lyase in woolly ripened long-term cold stored fruits $\left(\mathrm{E} 4: \mathrm{R}^{+}, \mathrm{C}^{+}\right)$ when compared to long-term cold stored fruits (E3: R', $\left.\mathrm{C}^{+}\right)$, the transcript levels in woolly fruits $\left(\mathrm{E} 4: \mathrm{R}^{+}, \mathrm{C}^{+}\right)$are still lower than the levels detected in juicy fruits $\left(\mathrm{E} 2: \mathrm{R}^{+}, \mathrm{C}^{-}\right.$ ). Alternatively, there may be a family of pectate lyase genes that are differentially expressed in the fruits, postharvest. It has been reported that in numerous species, pectate lyases are encoded by a large gene family [52]. We have identified three putative pectate lyases among our Unigenes (contigs 328, 1989 and 3683), suggesting that in peaches there is a pectate lyase gene family.

Trainotti et al [11] have demonstrated that three different expansin genes are expressed differentially during ripen- ing. Two of these expansin genes are up-regulated and one is down regulated in the S3/S4 transition [11]. We have identified seven contigs that are annotated as expansin or expansin family proteins (contigs 618, 1200, 1520, 1680, 2060, 2212 and 2420). The expansin genes analyzed by Trainotti et al [11] correspond to contigs 3786 and 1951 in our unigene sets. Interestingly, we have identified a novel expansin (contig 2212) that has increased transcript levels in woolly fruits when compared to juicy fruits. Since there are higher levels of the transcript for this contig in ripe, juicy fruits (E2: $\left.\mathrm{R}^{+}, \mathrm{C}^{-}\right)$in comparison to unripe fruits that have been stored for a long period of time (E3: $R^{-}$, $\mathrm{C}^{+}$), the increase in expansin levels in woolly fruits (E4: $\mathrm{R}^{+}, \mathrm{C}^{+}$) is occurring during the ripening process by a factor that cold storage has affected, and is not due to an increase in expansin levels in cold-stored fruits.

Trainotti et al [11] have also seen an increased expression of pectin methylesterase in S4I (climateric fruits that have not undergone softening, 115 days post-fertilization) and S4II ripened fruits (climateric fruits that have softened, 120-125 days post-fertilization). Our pair-wise comparison has detected an increased pectin methylesterase-like protein transcript (contig 2877) in woolly fruits when compared to juicy fruits. Increased transcripts that correspond to this contig were detected when comparing longterm cold storage fruits (E3: $\left.\mathrm{R}^{-}, \mathrm{C}^{-}\right)$with fruits from packing (E1: $\left.\mathrm{R}^{-}, \mathrm{C}^{-}\right)$. This suggests that the increase in this pectin methylesterase gene was induced by cold storage and remained elevated following ripening and the development of the woolly phenotype.

In addition to the changes in the expression of pectin methylesterase, we have detected eight pectin methylesterase inhibitor proteins in our Unigenes (contigs 59, 422, $741,1062,1945,2574,3374$ and 3598). Pair-wise analyses detected differential expression of three of these contigs (contigs 59, 1945 and 3598). Two of these contigs (contigs 59 and 3598) have similar patterns of differential expression under different post-harvest conditions. Both of these contigs have a reduced expression in ripe fruits with and without long-term cold storage (Additional File 2, Table S4-7). Contig 1945 also has a reduced expression in ripe juicy fruits. However, this contig has an increased expression in woolly ripened long-term cold stored fruits $\left(\mathrm{E} 4: \mathrm{R}^{+}, \mathrm{C}^{+}\right)$when compared to unripe fruits that have undergone long-term storage $\left(\mathrm{E} 3: \mathrm{R}^{-}, \mathrm{C}^{+}\right.$; Additional File 2, Table S6). In the model plant Arabidopsis, there is a family of pectin methylesterase inhibitors and invertases [53]. In vitro studies of pectin methylesterase inhibitors have been shown to have specific targets [53]. Therefore, the differential expression between the different contigs that code for pectin methylesterase inhibitors may have different targets. However, it is important to mention that these different contigs may be the product of different 
transcripts from a single locus, rather than a gene family. Future mapping of these ESTs to the peach physical map will help to clarify this possibility [54].

As mentioned earlier ethylene production has been shown to participate in peach fruit ripening $[10,39]$. We have detected an ACC oxidase gene (contig 1901) whose expression is increased in ripe fruits when compared to unripe fruits. However, there is a reduction in ACC oxidase (contig 1901) expression in woolly fruits $\left(\mathrm{E} 4: \mathrm{R}^{+}, \mathrm{C}^{+}\right)$ when compared to juicy fruits $\left(\mathrm{E} 2: \mathrm{R}^{+}, \mathrm{C}^{-}\right)$. This reduced expression of ACC oxidase may be associated with the wooliness phenotype. However, the ethylene production in the woolly fruits was higher than juicy fruits [3], suggesting that there are other genes associated with ethylene production that may also be altered.

We have also identified a number of genes associated with membrane formation and stress related genes that are differentially expressed under the different postharvest conditions analyzed. A large number of the genes that we have identified as being differentially expressed in response to cold, ripening or a combination of these two stimuli, have not been reported previously. Therefore, the large number of genes identified as having altered expression in response to the individual or combined effects of ripening and long-term cold storage, demonstrates the complexity of the processes that are occurring in peach fruits post harvest and the differential expression of gene families. Further analyses of the expression of these genes and the factors that cause this differential expression may provide interesting clues about the mechanisms associated with wooliness.

\section{Identification of genes that are co-expressed under different post-harvest conditions}

To identify clusters of genes that are co-expressed under different post-harvest conditions, a $k$-means analysis was performed to identify groups of genes with similar expression profiles. $K$-means clustering was performed using 13 different clusters with a maximum of 50 iterations, each containing between 78 and 161 genes (Figure 3). The optimal number of clusters was determined to be 13 by figure of merit analyses (Additional File 1, Figure S2).

Groups of clusters that correlate the gene expression profiles with the different post-harvest conditions are clearly visible when these groups are analyzed and compared (Figure 4, 5, and 6). One group (Figure 4) is represented by two clusters of genes (Clusters 4 and 12) whose expression profiles are inversely related in juicy, ripe fruits (E2: $\mathrm{R}^{+}, \mathrm{C}^{-}$), when compared to the other post harvest stages. Cluster 4 contains 107 genes with reduced expression exclusively in juicy, ripe fruits (E2: $\left.\mathrm{R}^{+}, \mathrm{C}^{-}\right)$, whereas cluster 12 contains 112 genes with increased expression exclu- sively in these same fruits. It is important to note this comparison is not a pair-wise comparison, rather a comparison between all four post-harvest conditions (E1: $\left.\mathrm{R}^{-}, \mathrm{C}^{-} ; \mathrm{E} 2: \mathrm{R}^{+}, \mathrm{C} ; \mathrm{E} 3: \mathrm{R}^{-}, \mathrm{C}^{+} ; \mathrm{E} 4: \mathrm{R}^{+}, \mathrm{C}^{+}\right)$. Clusters 4 and 12 reveal a decrease and increase in gene expression in juicy fruits, respectively, which is not present in woolly fruits. Genes that are differentially expressed in juicy fruits and not woolly fruits are genes that may be participating in the woolly phenotype. Analyses of these sequences and their corresponding Gene Ontology annotations reveal that ripe peaches have an increase in metabolic processes, especially processes associated with the metabolism of carbohydrates, nucleic acids, amino acids, lipids and secondary metabolites (Figure 4). In contrast, there is a decrease in translation, transport, and signal transduction processes. According to the GO annotations, it appears as though there is an increase in the expression of genes that are associated with mitochondria and plastids, as well as a decrease in those associated with ribosomes and the plasma membrane. Many of the metabolic process described earlier are carried out in the mitochondria and plastids, supporting this trend. The decrease in translation also correlates with the decrease in processes associated with the ribosome. These analyses suggest that woolly fruits lack the increased boost of metabolic processes necessary for ripening, such as the expression of cell wall modifying enzymes as well as the production of sugars and aromatic secondary metabolites. The changes in expression of cell wall modifying enzymes is consistent with what has been reported previously [1,9$13,39,48,51,55,56]$. However, these cluster analyses reveal the organelles that may actively participate in these processes as well as a large number of genes and gene families that should be analyzed for their participation in the altered metabolic processes present in woolly fruits.

In addition to the absence of the modified gene expression patterns seen in clusters 4 and 12, there is another pair of clusters that represent the opposite tendency. Clusters 1 and 9 (Figure 5) represent genes that change their expression exclusively in woolly fruits $\mathrm{E} 4(\mathrm{R}+\mathrm{C}+)$. Cluster 1 contains 94 genes with increased expression exclusively in woolly fruits, whereas cluster 9 contains 95 genes with decreased expression exclusively in woolly fruits. In these clusters, there is a notable increase in the expression of genes associated with processes such as translation, transport, response to abiotic stress and cellular organization and biogenesis. Interestingly, the combined results of clusters 4 and 1 (Figures 4 and 5) demonstrate that woolly fruits have lost the reduced expression of genes associated with transcription and translation. Additionally, following abiotic stress conditions such as long-term cold storage, it is not surprising to see increased expression of abiotic stress related genes in woolly fruits. However, it should be noted that this class of abiotic stress related 


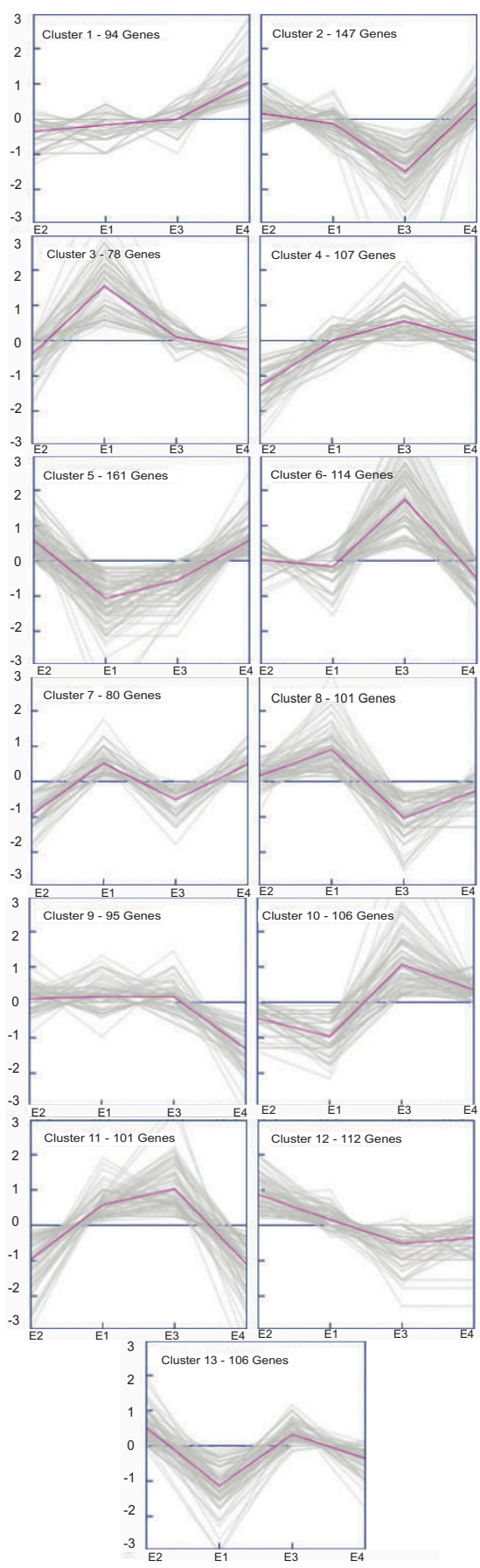

Figure 3

Expression profiles of clusters of genes with similar expression patterns. K-means clustering was performed with I,402 normalized Unigenes with five or more ESTs. Relative expression levels (log2 ratios) of these clusters of genes are shown at different post-harvest conditions, the mean expression values are represented by the magenta lines. Genes were grouped into I 3 clusters with distinct expression profiles. The optimal number of clusters was determined by Figure of Merit Analyses (Supplementary Figure S2). The expression levels for ripe juicy fruits that have not under-gone long-term cold storage, E2 ( $\mathrm{R}^{+}$, $\left.\mathrm{C}^{-}\right)$; non-ripe; non-long-term cold storage fruits, EI ( $\left.\mathrm{R}^{-}, \mathrm{C}^{-}\right)$; and non-ripe and ripe fruits that have undergone long-term cold storage, E3 $\left(R^{-}, C^{+}\right)$and $E 4\left(R^{+}, C^{+}\right)$, respectively, appear on the graphs. The total number of genes that make up each cluster is represented in the upper left hand corner of each cluster. 

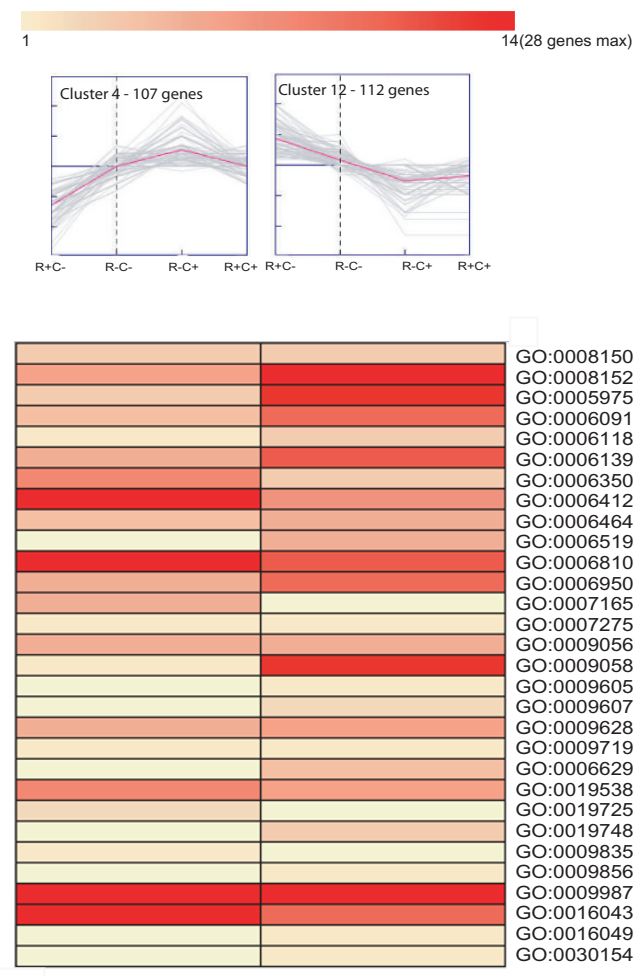

GO:0008150 biological_process

GO:0008152 metabolic process

(0)

GO:0006091 generation of precursor metabolites and energy

GO:0006118 electron transport

GO:0006139 nucleobase, nucleoside, nucleotide and nucleic acid metabolic process

GO:0006350 transcription

GO:0006412 translation

GO:0006519 amino acid and derivative metabolic process

GO:0006810 transport

GO:0006950 response to stress

GO:0007165 signal transduction

GO:0007275 multicellular organismal development

GO:0009056 catabolic process

GO:0009058 biosynthetic process

GO:0009605 response to external stimulus

GO:0009607 response to biotic stimulus

GO:0009628 response to abiotic stimulus

GO:0009719 response to endogenous

GO:0006629 lipid metabolic process

GO:0019538 protein metabolic proces

GO:0019725 cellular homeostasis

GO:0009835 ripening

GO:0009835 ripening

GO:0009987 cellular process

GO:0016043 cellular component organization and biogenesis

GO:0016049 cell growth

GO:0030154 cell differentiation

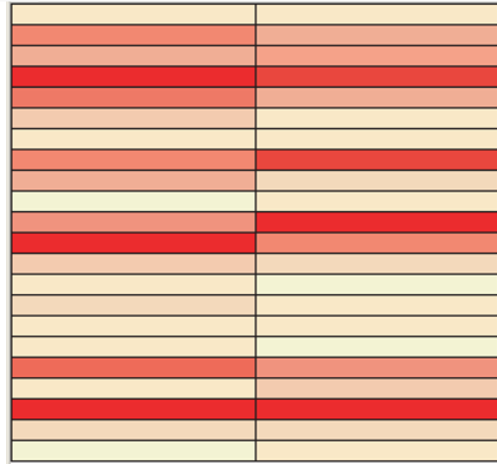

GO:0005623 cell

GO:0005618 cell wall

GO:0005622 intracellular

GO:0005737 cytoplasm

GO:0005829 cytosol

GO:0005783 endoplasmic reticulum

GO:0005794 Golgi apparatus

GO:0005739 mitochondrion

GO:0005773 vacuole

GO:0005777 peroxisom

GO:0009536 plastid

GO:0005840 ribosome

GO:0005634 nucleus

GO:0005635 nuclear envelope

GO:0005654 nucleoplasm

GO:0005730 nucleolus

GO:0005856 cytoskeleton

GO:0005886 plasma m

GO:0009579 thylakoid

G.:0016020 membrane

GO:0005576 extracellular region

\section{Figure 4}

Gene clusters with inverse expression profiles exclusively in ripened fruits. Cluster 4 (left) contains 107 genes that have reduced expression exclusively in juicy, mature fruits (E2: $\left.R^{+}, C^{-}\right)$, whereas cluster I2 (right) contains II 2 genes with increased expression exclusively in these same fruits. The Gene Ontology annotations of the genes in these clusters are represented below each cluster. The number of genes associated with each GO term is represented by the color of the bars, as depicted in the scale presented in this figure. The dashed line indicates non-ripe fruits, EI (R-, $\left.C^{-}\right)$. To the left of the dashed line is the expression levels for ripe, juicy fruits, E2 $\left(R^{+}, C^{-}\right)$. To the right of the dashed line are E3 $\left(R^{-}, C^{+}\right)$and E4 $\left(R^{+}, C^{+}\right)$fruits, non-ripe and ripe fruits that have undergone long-term cold storage, respectively. $\mathrm{E} 4\left(\mathrm{R}^{+}, \mathrm{C}^{+}\right)$fruits are wooly. GO annotations correspond to the parental plant GO Slim terms.

genes are distinct from those identified exclusively in the cold (Figure 6). As was seen in clusters 4 and 12, many of the differentially expressed genes that are differentially expressed exclusively in woolly fruits appear to be associated with the mitochondria, plastids and ribosomes. The participation of the mitochondria and plastids also correlate well with the increase in respiration that was detected in these fruits [3]. The plasma membrane is also participating, possibly associated with abiotic stress responses such as cold and/or desiccation stresses.

The identification of genes that are associated with mitochondrial and plastid processes, as well as the differential expression of genes such as glutathione peroxidase, sug- 

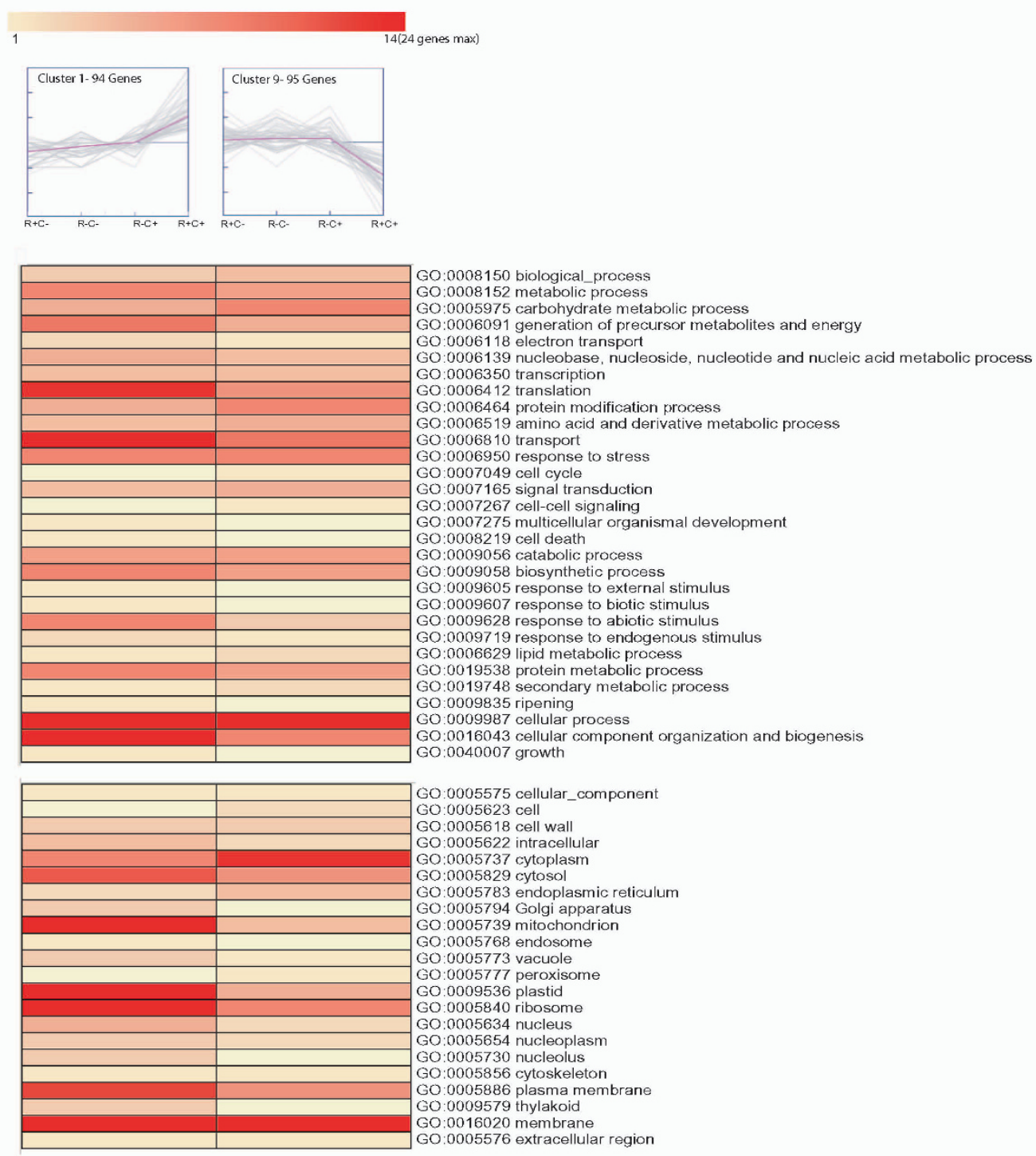

\section{Figure 5}

Gene clusters with inverse expression profiles exclusively in woolly fruits. Cluster I (left) contains 94 genes that have increased expression exclusively in fruits that are wooly $\left(E 4: R^{+}, C^{+}\right)$, whereas cluster 9 (right) contains 95 genes with decreased expression exclusively in these same fruits. The Gene Ontology annotations of the genes in these clusters are represented below each cluster. The number of genes associated with each $\mathrm{GO}$ term is represented by the color of the bars, as depicted in the scale presented in this figure. The dashed line indicates non-ripe fruits, EI ( $\left.R^{-}, C^{-}\right)$. To the left of the dashed line is the expression levels for ripe, juicy fruits, E2 $\left(R^{+}, C^{-}\right)$. To the right of the dashed line are $E 3\left(R^{-}, C^{+}\right)$and $E 4\left(R^{+}, C^{+}\right)$fruits, non-ripe and ripe fruits that have undergone long-term cold storage, respectively. $E 4\left(R^{+}, C^{+}\right)$fruits are wooly. Annotations correspond to the parental plant GO Slim terms.

gests that oxidative stress and metabolic imbalances may play a major role in wooliness. Interestingly, recent publications have presented physiological analyses that support this hypothesis [57-59].

Yet another group represents genes that are differentially expressed exclusively in unripe fruits that have undergone long-term cold storage E3 ( $\mathrm{R}^{-}, \mathrm{C}^{+}$; Figure 6). This group is represented by clusters 2 and 6 . Cluster 2 contains 147 genes with reduced expression exclusively in non-ripe fruits that have undergone a long-term cold storage (E3: R, $\left.\mathrm{C}^{+}\right)$, whereas cluster 6 contains 114 genes with increased expression exclusively in these same fruits. Surprisingly, only 4 of the genes, present in cluster 6 correspond to 

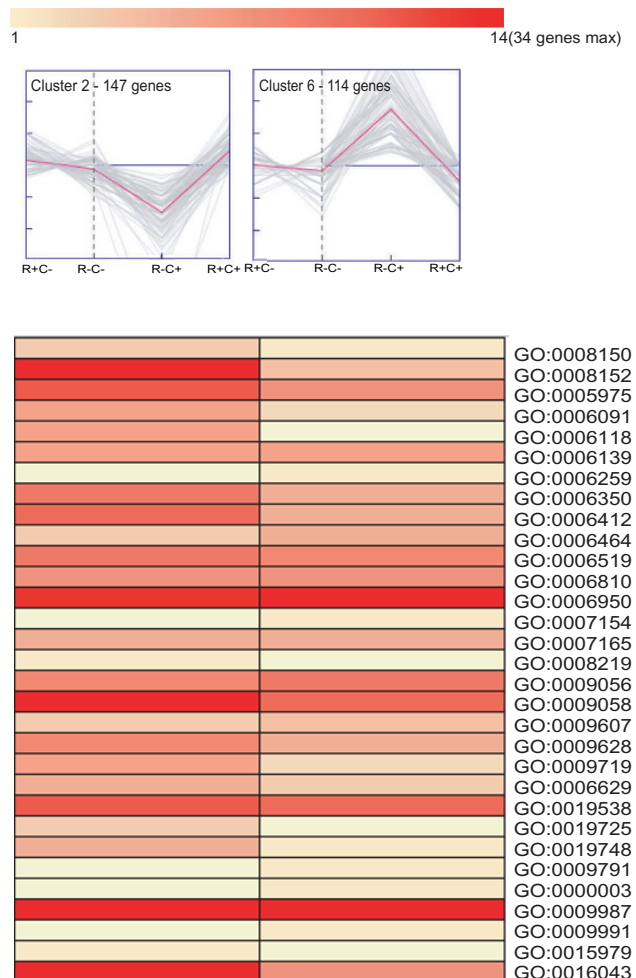

GO:0008150 biological_process GO:0008152 metabolic process GO:0005975 carbohydrate metabolic process GO:0006091 generation of precursor metabolites and energy GO:0006118 electron transport

GO:0006139 nucleobase, nucleoside, nucleotide and nucleic acid metabolic process GO:0006259 DNA metabolic process GO.0006350 transcription GO:0006412 translation

GO:0006519 amino acid and derivative metabolic process

GO:0006810 transport

GO:0006810 transport

GO:0007165 signal transduction

GO:0008219 cell death

GO:0009056 catabolic process

GO:0009058 biosynthetic process

GO:0009607 response to biotic stimulus

GO:0009628 response to abiotic stimulus

GO:0009719 response to endogenous stimulus

GO:0006629 lipid metabolic process

GO:0019538 protein metabolic process

GO:0019725 cellular homeostasis

GO:0019748 secondary metabolic process

GO:0009791 post-embryonic development

GO:0000003 reproduction

GO:0009987 cellular process

GO:0009991 response to extrac

GO:0016043 cellular component organization and biogenesis

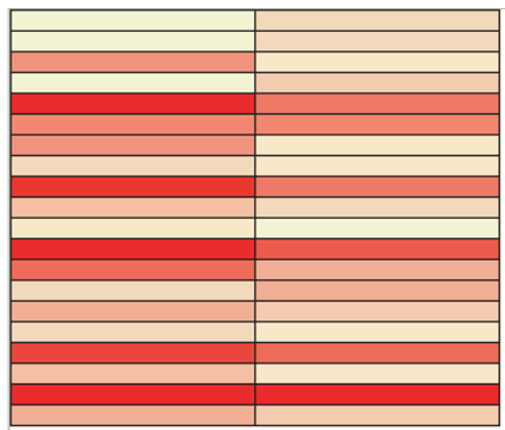

GO:0005575 cellular_component

GO:0005623 cell

GO:0005618 cell wall

GO:0005622 intracellular

GO:0005737 cytoplas

GO:0005783 endoplasmic reticulum

GO:0005794 Golgi apparatus

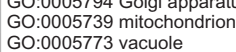

GO:0005777 peroxisome

GO:0009536 plastid

GO:0005840 ribosome

GO:0005634 nucleus

GO:0005654 nucleoplasm

GO:0005856 cytoskeleton

GO:0005886 plasma membrane

GO:0009579 thylakoid

GO:0016020 membrane

\section{Figure 6}

Gene clusters with inverse expression profiles exclusively in fruits that have undergone long-term cold storage. Cluster 2 (left) contains 147 genes that have reduced expression exclusively in fruits that have undergone long-term cold storage (E3: R-, $C^{+}$), whereas cluster 6 (right) contains II 4 genes with increased expression exclusively in these same fruits. The Gene Ontology annotations of the genes in these clusters are represented below each cluster. The number of genes associated with each GO term is represented by the color of the bars, as depicted in the scale presented in this figure. The dashed line indicates non-ripe fruits, El ( $\left.R^{-}, C^{-}\right)$. To the left of the dashed line is the expression levels for ripe, juicy fruits, E2 ( $\left.R^{+}, C^{-}\right)$. To the right of the dashed line are E3 $\left(R^{-}, C^{+}\right)$and $E 4\left(R^{+}, C^{+}\right)$fruits, non-ripe and ripe fruits that have undergone long-term cold storage, respectively. $\mathrm{E} 4\left(\mathrm{R}^{+}, \mathrm{C}^{+}\right)$fruits are wooly. GO annotations correspond to the parental plant GO Slim terms.

genes identified as being differentially expressed by Ogundiwin et al [13]. Differentially expressed genes, identified by Ogundiwin et al [13], appear in clusters 6, 7, 11 and 12 . Therefore, we have identified a very large number of novel genes that are associated specifically with the unripe fruits that have undergone long-term cold storage. These genes are associated with a large number of biolog- ical processes in multiple regions of the cell. By further analyzing the function of these genes we may be able to better understand the specific modifications that have occurred in the fruit under long-term cold storage that ultimately results in the modification in the ripening process that result in woolly fruits. 


\section{Conclusion}

By sequencing a large number of ESTs from cDNA libraries representing peach mesocarp from four different postharvest conditions, we have begun to identify the individual and combined effects that long-term cold storage (C) and ripening $(\mathrm{R})$ have on the transcripts in this tissue.

10,830 Unigenes (4,169 contigs and 6,661 singletons) were formed by assembling a total of 41,519 ESTs. These EST sequences have been deposited in Genbank and the sequence information associated with the Unigenes is available at http://www.genomavegetal.cl/juice/EST. Additionally, since the libraries that were used in this sequencing effort were enriched for large inserts and are cloned within two flanking lox-P sites in the pDNR-1r vector (Clontech), we have a collection of full-length clones which may be easily recombined with vectors that contain single loxP sites, for rapid cloning into other expression vectors and for functional analyses of these genes.

In addition to the sequence information and full-length clones developed in this work, digital analyses of EST abundance in the four different post-harvest conditions has revealed a large number of candidate genes with fluctuating transcript levels in response to factors such as ripening, long-term cold storage and a combination of these two factors (ripening + long-term cold storage).

These analyses have enabled us to statistically identify novel genes and gene clusters that are differentially expressed in response to post-harvest factors such longterm cold storage, ripening and/or a combination of these two factors. These differentially expressed genes reveal the participation of specific metabolic processes that normally occur in ripen fruits that do not occur in woolly fruits, as well as novel processes that are occurring in the woolly fruits that are not normally present in ripen fruits.

These analyses also demonstrate the need to better identify and understand the specificity and expression of gene families and/or different transcripts from a single gene in post-harvest processes. Additionally, these analyses present data that suggests that wooliness is not only due to modifications of the cell wall, but may also include stress response pathways and oxidative damage.

The EST sequences and full-length cDNA clones developed in this work, combined with the large population of differentially expressed genes may serve as useful tools and markers that will enable the scientific community to better understand the molecular and cellular processes that affect fruit quality in response to post-harvest conditions and the large number of gene products that participate in these processes. By understanding these processes, this knowledge may be used in the future to improve postharvest fruit quality.

\section{Methods cDNA library construction}

Prunus persica var. persica (L.) Batch cv. O'Henry fruits were selected as the source of material for the construction of the cDNA libraries. Mesocarp tissue was collected from fruits at four different post-harvest conditions. The postharvest conditions include: fruits processed in a packing plant (E1: R-C: non-ripe; no long-term cold storage); packing followed by a shelf life at $20^{\circ} \mathrm{C}$ for $2-6$ days (E2: $\mathrm{R}^{+} \mathrm{C}$ : ripe; no long-term cold storage; juicy fruits); packing followed by cold storage at $4{ }^{\circ} \mathrm{C}$ for 21 days (E3: $\mathrm{R}^{-\mathrm{C}^{+}}$: non-ripe; long-term cold storage) and packing followed by cold storage at $4{ }^{\circ} \mathrm{C}$ for 21 days and shelf life at $20^{\circ} \mathrm{C}$ for 2-6 days $\left(\mathrm{E} 4: \mathrm{R}^{+} \mathrm{C}^{+}\right.$: ripe; long-term cold storage; woolly fruits). In order to ensure that all fruits were similar in size and quality, fruits were selected in a commercial peach packing plant prior to postharvest treatment. The mesocarp tissue used for library construction corresponds to the fruits harvested in Year 1 (2003) and reported in Campos-Vargas et al [3]. The juice content (woolliness), maturity (ground color, firmness, total soluble solids) and physiological parameters (respiration rate and ethylene production) of the fruit tissue are described in Campos-Vargas et al (Year 1) [3].

We have previously reported the quality of these libraries (\% Recombination and Clone Range) [60]. During the cDNA synthesis process, an adaptor containing an XhoI restriction site (5'-GAC TAG TTC TAG ATC GCG ACT CGAGCC- $\left.(T)_{15}-3^{\prime}\right)$ was incorporated to the 3 ' end of the cDNA. cDNAs were enriched for large fragments and these fragments were subsequently cloned directionally into the pDNR-1r vector (Clontech) at the XhoI -SmaI sites. The clone codes uploaded in GenBank are PU1 for E1, PU2 for E2, PU3 for E3 and PU4 for E4.

\section{Sequencing and assembly}

Arrayed cDNA clones from the four libraries were Sanger sequenced at the 5' end, using the M13 Forward primer. The EST data files received were used in our sequence analysis pipeline as shown in Figure 1. Sequence chromatograms were read with PHRED base calling software $[61,62]$. Only those ESTs that contained an average Phred $\mathrm{Q}>20$ between bases 100 and 300 were used for further analyses. Selected EST sequences were filtered in order to improve the quality of sequence assemble. These filters include: masking of bases that correspond to vector sequence, detection and filtering of reverse ligations or sequences with greater than 40 sequential Ts. Masked bases were subsequently removed. A 3 ' end quality filter was applied and sequences shorter than 100 bps were 
eliminated from further analyses. Sequences that passed these filters were assembled using CAP3 95/60 (-p 95 -d 60) [63].

\section{Annotation}

Unigenes and ESTs were annotated based on accumulative bioinformatics evidence [64]. This evidence was obtained using BLAST [25] and InterProScan [26] against the following databases: GenBank (http:// www.ncbi.nlm.nih.gov/, Jan 2008 release); TAIR (http:// www.arabidopsis.org/, Jul 2007 release), and GDR (http:/ Lwww.mainlab.clemson.edu/gdr/, March 2007 release). BLAST-based annotations were performed using BLASTn and BLASTx (BLOSUM62). InterProScan analyses integrate the PROSITE, PRINTS, Pfam, ProDom, SMART and TIGRFAMs databases [26]. All putative annotations with an E-value $>10^{-7}$ were selected and categorized according to the percentage of identity, length of coverage and the existence of gaps. Computational evidence associated with predicted gene structure and protein domains were also taken into consideration. This information was gathered and curate manually. Once validated, gene products were named according to the degree of similarity, structure and protein domains. To our knowledge, a standard nomenclature does not exist for peach annotations; therefore, we adapted our annotation protocol to include the prefixes and suffixes used by TAIR, TGR and RIKENs [65]. These prefixes and suffixes illustrate the degree of confidence based on computational evidence. The results of these analyses were stored in the JUICE data management system [27].

Functional classification of the Unigenes and ESTs were performed by assigning Gene Ontology annotation codes [66], based upon homology information gathered from the BLAST, BLAST2GO and InterProScan analyses [22-26].

Comparisons between ESTs and/or Unigenes were performed by mapping the GO annotations to their parent plant GO Slim terms using map2slim.pl script http:// search.cpan.org/ cmungall/go-perl[67]. Only the matches with E-values less than $1 \mathrm{e}^{-7}$ were included in the analysis. Unigenes were classified into multiple GO Slim Plant categories [68].

To find contaminating sequences, a BLASTn match with an alignment greater than $100 \mathrm{bp}$ was used $(\geq 90 \%$ and evalue $\leq$ than $10^{-7}$ ) [69]. EST sequences that met these criteria were not assigned GO annotations and were excluded from digital expression analyses since they are nearly identical to viral, fungal or bacterial sequences and, therefore, may represent contaminations.

Novel EST sequences were determined by performing BLASTn against the sequence information available in the public databases such as NCBI, ESTree, ChillPeach and PlantTA [13,17-19]. A sequence that does not contain novel sequence information is defined as those unigene consensus sequences that have $\geq 95 \%$ percent-length and $\geq 50 \%$ coverage with other published sequences. Sequences that did not meet these criteria are defined as sequences that contain novel sequence information.

\section{Digital gene expression profile}

Gene expression profiles were analyzed statistically to determine if the Unigenes were differentially expressed under different post-harvest conditions using the Winflat program that submits the sequence data to a rigorous statistical analysis described by Audic and Claverie http://igsserver.cnrs-mrs.fr[32]. This approach allows differentially expressed genes $(p<0.01)$ to be identified from pair-wise cDNA library comparisons.

To identify groups of genes with similar expression profiles, coordinated gene expression analyses were performed on the peach EST data from the four cDNA libraries. Only contigs composed of at least five ESTs were used in making the expression profile matrix [31]. A hierarchical clustering method was applied to compare differential expression of these contigs. The number of ESTs in each post-harvest condition was normalized proportionally to the total number of ESTs in their corresponding contig. The displayed expression profile was normalized $(\log 2)$. The green color indicates fewer and red indicates a greater number of ESTs than the norm for each contig [70].

To identify groups of co-expressed genes, we use the $k$ means method $[71,72]$ with Pearson's correlation coefficient using the Genesis software tools [73] to cluster contigs that contain at least five ESTs. To determinate the optimal number of clusters, Figure of Merit (FOM) analyses were calculated to determine the quality of the clusters [74].

\section{qPCR analysis}

Total RNA was prepared from E1, E2, E3 and E4 using the method described by Meisel et al [60]. cDNA was synthesized from $2.5 \mu \mathrm{g}$ of total RNA using ImProm-IITM Reverse Transcription System kit (Promega) in $20 \mu \mathrm{L}$ of reaction mixture. As a control, samples were spiked with $0.5 \mathrm{pg}$ of Kanamycin RNA. $0.1 \mu \mathrm{L}$ of the cDNA was added to $20 \mu \mathrm{L}$ of PCR mixture containing each primer $(0.2-0.5$ $\mu \mathrm{M})$, fast SYBR green master mix $(2 \times)$ from Applied Biosystems. After heating at $95^{\circ} \mathrm{C}$ for $20 \mathrm{sec}$, PCR reactions proceeded through 45 cycles of 3 seconds at $95^{\circ} \mathrm{C}, 5$ to 20 seconds at $60-62^{\circ} \mathrm{C}$. The amount of the amplified DNA was monitored by fluorescence at the end of each cycle using Step One Real Time PCR System (Applied Biosys- 
tems). The primers used for qRT-PCR are described in Additional File 1, Table S3.

Quantification was based on the fact that the cycle threshold value (cycle number required to obtain a fluorescence signal above the background) correlates inversely with the log of the initial template concentration [75]. The relative abundance of the targeted mRNAs from several samples was determined from a standard curve that was constructed from a set of DNA dilutions from each one of the transcripts to be analyzed. To standardize the results, we used qRT-PCR for the dehydrogenase/GMP reductase (contig 2766), gene that under our experimental conditions does not show changes in transcript levels. The primers for dehydrogenase/GMP reductase are also described in Additional File 1, Table S3.

\section{Identification of full-length EST cDNA clones}

The cDNA libraries were enriched for large fragments [60]. The consensus sequences of the Unigenes were analyzed with EuGeneHom [28], in order to identify the Unigenes that contained the components of a complete cDNA (5' UTR, ORF and 3' UTR) http://bioinfo.genopole-tou louse.prd.fr/apps/eugene/EuGeneHom/cgi-bin/EuGene Hom.pl.

\section{Authors' contributions}

PV annotated and curated the sequences and performed the k-means analyses. PV and AT performed the digital expression analyses. PV, ML, JS, LM and HS developed and implemented the assembly, annotation and bioinformatics analyses of the sequences. RC and PV performed the qPCR analyses. RC-V performed the postharvest treatment of the fruits; HS and LM conceived, supervised and participated in all analyses. PV, HS and LM drafted the manuscript. HS, VC, RC, MG, AO and LM supervised the Chilean Functional Genomics Consortium in Nectarines which provided the platform for this EST project workflow. All authors read and approved the manuscript.

\section{Additional material}

\footnotetext{
Additional file 1

Supplementary Tables S1 - S3, Supplementary Figures S1 and S2. This file contains additional information about the sequence analyses as well the primers used for qRT-PCR analyses. There are a total of three tables and figures. The titles of these tables and figures are as follows: Table S1 - Number of "Good Quality" ESTs sequenced from each post-harvest condition; Table S2 - Distribution of ESTs in Contigs; Table S3 - Primer sequences sets for qRT-PCR analyses of representative differentially expressed contigs; Figure S1 - The distribution of peach mesocarp derived ESTs under four different post-harvest conditions, using hierarchical clustering; Figure S2 - Figure of Merit Analysis.

Click here for file

[http://www.biomedcentral.com/content/supplementary/14712164-10-423-S1.doc]
}

\section{Additional file 2}

Supplementary Tables S4 - S7. This file contains the contigs that digital expression analyses revealed are differentially expressed in different postharvest conditions. The titles for these tables are as follows: Table S4 Contigs that are differentially expressed between ripe peach fruits (E2: $R+$, $C-)$ and unripe fruits (E1: $R-, C$-); Table S5 - Contigs that are differentially expressed between unripe peach fruits that have undergone longterm cold storage (E3: $R-, C+)$ and unripe peach fruits that have not (E1: $R-, C-) ;$ Table S6 - Contigs that are differentially expressed between ripen peach fruits that have undergone long-term cold storage $(E 4: R+, C+)$ and unripe peach fruits that have undergone long-term cold storage (E3: $R$-, $C+)$; Table S7 - Contigs that are differentially expressed between ripen peach fruits that have undergone long-term cold storage $\left(E 4: R^{+}, C^{+}\right)$and ripen peach fruits that have not undergone long-term cold storage (E2: $R^{+}$, $\left.C^{-}\right)$.

Click here for file

[http://www.biomedcentral.com/content/supplementary/14712164-10-423-S2.xls]

\section{Acknowledgements}

We would like to thank: Manuel Bugueño and Simon Segovia for their technical assistance in confirming the size of the cDNA inserts, Andrea Morales for her technical assistance in qPCR analysis, Nicolas Loira for his informatics assistance with the preliminary analyses of the EST sequences and Oscar Becerra for his technical assistance in harvesting and treating the fruits.

This work was supported by ICM P06-065-F, FDI G02PI00I (Chilean Genome Initiative) with funding from the Chilean government as well as ASOEX (Asociación de Exportadores de Chile A.G.), FDF (Fundación para el Desarrollo Frutícola) and Fundación Chile, Proyecto Consorcio BIOFRUTALES S.A., PBCT RII, and UNAB DI-20-09/I.

\section{References}

I. Lurie $\mathrm{S}$, Crisosto $\mathrm{CH}$ : Chilling injury in peach and nectarine. Postharvest Biology and Technology 2005, 37: 195-208.

2. Lill R, O'Donoghue E, King G: Postharvest physiology of peaches and nectarines. Hort Rev 1989, I I:413-452.

3. Campos-Vargas R, Becerra O, Baeza-Yates R, Cambiazo V, Gonzalez M, Meisel L, Orellana A, Retamales J, Silva H, Defilippi BG: Seasonal variation in the development of chilling injury in 'O'Henry' peaches. Scientia Horticulturae 2006, I I 0(I):79-83.

4. Retamales J, Cooper T, Streif J, Kania J: Preventing cold storage disorders in nectarines. J Hort Sci 1992, 67:619-626.

5. Crisosto $\mathrm{CH}$, Mitchell FG, Johnson S: Factors in fresh market stone fruit quality. Postharvest News and Information 1995, 6(2): $17-2 \mid$.

6. Crisosto C, Mitchell F, Ju Z: Susceptibility to chilling injury of peach, nectarine, and plum cultivars grown in California. HortScience 1999, 34:11116-11118.

7. Retamales J, Defilippi B, Campos R: Control of cold storage disorders in nectarines by modified atmosphere packaging. Fruits 2000, 55:213-219.

8. Meisel L: The Chilean Gene Hunt: a functional genomics approach towards identifying candidate genes associated with peach/nectarine fruit quality. Summer Fruit 2006, 8(2): 17.

9. Brummell DA, Dal Cin V, Lurie S, Crisosto CH, Labavitch JM: Cell wall metabolism during the development of chilling injury in cold-stored peach fruit: association of mealiness with arrested disassembly of cell wall pectins. J Exp Bot 2004, 55(405):204|-2052.

10. Trainotti L, Pavanello A, Zanin D: PpEG4 is a peach endo-betaI,4-glucanase gene whose expression in climacteric peaches does not follow a climacteric pattern. J Exp Bot 2006, 57(3):589-598. 
1I. Trainotti L, Zanin D, Casadoro G: A cell wall-oriented genomic approach reveals a new and unexpected complexity of the softening in peaches. J Exp Bot 2003, 54(389): $1821-1832$

12. Gonzalez-Aguero M, Pavez L, Ibanez F, Pacheco I, Campos-Vargas R, Meisel LA, Orellana A, Retamales J, Silva H, Gonzalez M, et al.: Identification of woolliness response genes in peach fruit after post-harvest treatments. J Exp Bot 2008, 59(8):1973-1986.

13. Ogundiwin EA, Marti C, Forment J, Pons C, Granell A, Gradziel TM, Peace CP, Crisosto CH: Development of ChillPeach genomic tools and identification of cold-responsive genes in peach fruit. Plant Mol Biol 2008, 68(4-5):379-397.

14. Kader AA: Cold storage potential of cling peach varieties. Cling Peach Quart 1985, 2 I (1): 18-19.

15. Von Mollendorf LJ: Wooliness in peaches and nectarines: a review. I. Maturity and external factors. Hort Sci 1987, 5: I-3.

16. DeGroot MH: Probability and statistics. Reading, Mass.: AddisonWesley Pub. Co; 1975.

17. Lazzari B, Caprera A, Vecchietti A, Merelli I, Barale F, Milanesi L, Stella $A$, Pozzi C: Version VI of the ESTree db: an improved tool for peach transcriptome analysis. BMC Bioinformatics 2008, 9(Suppl 2):S9.

18. Lazzari B, Caprera A, Vecchietti A, Stella A, Milanesi L, Pozzi C: ESTree db: a tool for peach functional genomics. BMC Bioinformatics 2005, 6(Suppl 4):SI6.

19. Childs KL, Hamilton JP, Zhu W, Ly E, Cheung F, Wu H, Rabinowicz PD, Town CD, Buell CR, Chan AP: The TIGR plant transcript assemblies database. Nucleic Acids Res 2007, 35:D846-D85I.

20. Jung $S$, Jesudurai $C$, Staton M, Du ZD, Ficklin S, Cho IH, Abbott $A$ Tomkins J, Main D: GDR (Genome Database for Rosaceae): integrated web resources for Rosaceae genomics and genetics research. $B M C$ Bioinformatics 2004, 5: 130 .

21. Jung $S$, Staton $M$, Lee T, Blenda A, Svancara R, Abbott $A$, Main $D$ : GDR (Genome Database for Rosaceae): integrated webdatabase for Rosaceae genomics and genetics data. Nucleic Acids Res 2008, 36:DI034-DI040.

22. Gotz S, Garcia-Gomez JM, Terol J, Williams TD, Nagaraj SH, Nueda MJ, Robles M, Talon M, Dopazo J, Conesa A: High-throughput functional annotation and data mining with the Blast2GO suite. Nucleic Acids Res 2008, 36( I 0):3420-3435.

23. Conesa A, Gotz S: Blast2GO: A Comprehensive Suite for Functional Analysis in Plant Genomics. Int J Plant Genomics 2008:619832.

24. Conesa A, Gotz S, Garcia-Gomez JM, Terol J, Talon M, Robles M: Blast2GO: a universal tool for annotation, visualization and analysis in functional genomics research. Bioinformatics 2005 , 2I(18):3674-3676.

25. Altschul SF, Gish W, Miller W, Myers EW, Lipman DJ: Basic local alignment search tool. J Mol Biol 1990, 2I 5(3):403-4I0.

26. Zdobnov EM, Apweiler R: InterProScan--an integration platform for the signature-recognition methods in InterPro. Bioinformatics 200I, 17(9):847-848.

27. Latorre M, Silva H, Saba J, Guziolowski C, Vizoso P, Martinez V, Maldonado J, Morales A, Caroca R, Cambiazo V, et al.: JUICE: a data management system that facilitates the analysis of large volumes of information in an EST project workflow. BMC Bioinformatics 2006, 7:513

28. Foissac S, Bardou P, Moisan A, Cros MJ, Schiex T: EUGENE'HOM: A generic similarity-based gene finder using multiple homologous sequences. Nucleic Acids Res 2003, 3 I (I 3):3742-3745.

29. Abremski K, Hoess R: Bacteriophage PI site-specific recombination. Purification and properties of the Cre recombinase protein. | Biol Chem 1984, 259(3): |509-| 5 |4.

30. Sauer B: Site-specific recombination: developments and applications. Curr Opin Biotechnol 1994, 5(5):52I-527.

31. Eisen M, Spellman PT, Brown PO, Botstein D: Cluster analysis and display of genome-wide expression patterns. Proc Natl Acad Sci USA 1998, 95(25): 14863-14868.

32. Audic $S$, Claverie J: The significance of digital gene expression profiles. Genome Res 1997, 7(10):986-995.

33. Alexander L, Grierson D: Ethylene biosynthesis and action in tomato: a model for climacteric fruit ripening. J Exp Bot 2002, 53(377):2039-2055.

34. Bleecker $A B$, Kende $H$ : Ethylene: a gaseous signal molecule in plants. Annu Rev Cell Dev Biol 2000, 16:1-18.

35. Giovannoni J: Molecular Biology of Fruit Maturation and Ripening. Annu Rev Plant Physiol Plant Mol Biol 200I, 52:725-749.
36. Giovannoni J]: Genetic Regulation of Fruit Development and Ripening. Plant Cell 2004, 16:SI70-I80.

37. Hayama H, Shimada T, Fujii H, Ito A, Kashimura Y: Ethylene-regulation of fruit softening and softening-related genes in peach. J Exp Bot 2006, 57( (15):407I-4077.

38. Ruperti B, Bonghi C, Rasori A, Ramina A, Tonutti P: Characterization and expression of two members of the peach I-aminocyclopropane-I-carboxylate oxidase gene family. Physiol Plant 200I, III(3):336-344

39. Trainotti L, Bonghi C, Ziliotto F, Zanin D, Rasori A, Casadoro G, Ramina A, Tonutti P: The use of microarray $\mu$ PEACHI.0 to investigate transcriptome changes during transition from pre-climacteric to climacteric phase in peach fruit. Plant Science 2006, I70(3):606-6I3.

40. Lester DR, Speirs J, Orr G, Brady Cl: Peach (Prunus persica) endopolygalacturonase cDNA isolation and mRNA analysis in melting and nonmelting peach cultivars. Plant Physiol I994, I05(I):225-23I.

4I. Pressey R, Avants JK: Differences in polygalacteronase composition of clingstone and freestone peaches. J Food Sci 1978, 43: $1415-1423$.

42. Cao SF, Zheng YH, Wang KT, Jin P, Rui HJ: Methyl jasmonate reduces chilling injury and enhances antioxidant enzyme activity in postharvest loquat fruit. Food Chemistry 2009, I I 5(4): I 458-1463.

43. Hodge DM, ed: Postharvest Oxidative Stress in Horticultural Crops. Binghamton, NY: Haworth Press; 2003.

44. Mittler R, Vanderauwera S, Gollery M, Van Breusegem F: Reactive oxygen gene network of plants. Trends in Plant Science 2004, 9(10):490-498.

45. Prasad TK, Anderson MD, Stewart CR: Acclimation, Hydrogen Peroxide, and Abscisic Acid Protect Mitochondria against Irreversible Chilling Injury in Maize Seedlings. Plant Physiol 1994, 105(2):619-627.

46. Ben Arie R, Lavee S: Pectic changes occurring in Elberta peaches suffering from woolly breakdown. Phytochemistry | $97 \mid$, 10:531-538.

47. Buerscher R, Furmanski R: Role of pectinesterase and polygalacturonase in the formation of woolliness in peaches. J Food $\mathrm{Sci}$ 1978, 43:264-266.

48. Zhou H, Ben-Arie R, Lurie S: Pectin esterase, polygalacturonase and gel formation in peach pectin fractions. Phytochemistry 2000, 55(3): $191-195$

49. Zhou H, Lurie S, Lers A, Khatchitski A, Sonego L, Ben Arie R: Delayed storage and controlled atmosphere storage of nectarines: two strategies to prevent woolliness. Postharvest Biol Technol 2000, I8:|33-|4|.

50. Ben Arie R, Sonego L: Pectolytic enzyme activity involved in woolly breakdown of stored peaches. Phytochemistry 1980, 19:2553-2555.

51. Peace CP, Crisosto $\mathrm{CH}$, Gradziel TM: Endopolygalacturonase: $\mathbf{A}$ candidate gene for Freestone and Melting flesh in peach. Molecular Breeding 2005, I6(I):21-3I.

52. Marin-Rodriguez MC, Orchard J, Seymour GB: Pectate lyases, cell wall degradation and fruit softening. J Exp Bot 2002, 53(377):2115-2119.

53. Rausch T, Greiner S: Plant protein inhibitors of invertases. Biochimica Et Biophysica Acta-Proteins and Proteomics 2004 1696(2):253-26|.

54. Jung $S$, Staton M, Lee T, Blenda A, Svancara R, Abbott A, Main D: GDR (Genome Database for Rosaceae): integrated webdatabase for Rosaceae genomics and genetics data. Nucl Acids Res 2008, 36(suppl_I):DI034-1040.

55. Criel B, Hausman F, Oufir M, Swennen R, Panis B, Renaut J: Proteome and sugar analysis of abiotic stress underlying cryopreservation in potato. Commun Agric Appl Biol Sci 2006, 7 I ( I ):3-6.

56. Zhou $\mathrm{H}$, Sonego L Khalchitski A, Ben Arie R, Lers A, Lurie A: Cell wall enzymes and cell wall changes in 'Flavortop' nectarines: mRNA abundance, enzyme activity, and changes in pectic and neutral polymers during ripening and in woolly fruit. Am Soc Hort Sci 2000, I 25:630-637.

57. Flores FB, Sánchez-Bel P, Valdenegro M, Romojaro F, MartínezMadrid MC, Egaea Ml: Effects of a pretreatment with nitric oxide on peach (Prunus persica L.) storage at room temperature. Eur Food Res Technol 2008, 227(6):|599-1611. 
58. Jin $\mathrm{P}$, Zheng $\mathrm{Y}$, Tang $\mathrm{S}$, Rui $\mathrm{H}$, Wang $\mathrm{CY}$ : A combination of hot air and methyl jasmonate vapor treatment alleviates chilling injury of peach fruit. Postharvest Biology and Technology 2009, 52(I):24-29.

59. Wang L, Chen S, Kong W, Li S, Archbold DD: Salicylic acid pretreatment alleviates chilling injury and affects the antioxidant system and heat shock proteins of peaches during cold storage. Postharvest Biology and Technology 2006, 4I(3):244-25I.

60. Meisel L, Fonseca B, Gonzalez S, Baeza-Yates R, Cambiazo V, Campos $\mathrm{R}$, Gonzalez M, Orellana A, Retamales J, Silva H: A rapid and efficient method for purifying high quality total RNA from peaches (Prunus persica) for functional genomics analyses. Biol Res 2005, 38(I):83-88.

61. Ewing B, Green P, Hillier L, WendI MC, Green P: Base-calling of automated sequencer traces using phred. I. Accuracy assessment. Genome Res 1998, 8(3): 175-185.

62. Ewing B, Green P: Base-calling of automated sequencer traces using phred. II. Error probabilities. Genome Res 1998, 8(3): $186-194$.

63. Huang $X$, Madan A: CAP3: A DNA sequence assembly program. Genome Res 1999, 9(9):868-877.

64. Bono H, Kasukawa T, Furuno M, Hayashizaki Y, Okazaki Y: FANTOM DB: database of Functional Annotation of RIKEN Mouse cDNA Clones. Nucleic Acids Res 2002, 30(1): I I6-I I8.

65. Maeda N, Kasukawa T, Oyama R, Gough J, Frith M, Engstrom PG, Lenhard B, Aturaliya RN, Batalov S, Beisel KW, et al:: Transcript annotation in FANTOM3: mouse gene catalog based on physical cDNAs. PLoS Genet 2006, 2(4):e62.

66. Ashburner M, Ball CA, Blake JA, Botstein D, Butler H, Cherry JM, Davis AP, Dolinski K, Dwight SS, Eppig JT, et al:: Gene ontology: tool for the unification of biology. The Gene Ontology Consortium. Nat Genet 2000, 25(I):25-29.

67. Berardini TZ, Mundodi S, Reiser L, Huala E, Garcia-Hernandez M, Zhang P, Mueller LA, Yoon J, Doyle A, Lander G, et al.: Functional annotation of the Arabidopsis genome using controlled vocabularies. Plant Physiol 2004, I 35(2):745-755.

68. Clark Jl, Brooksbank C, Lomax J: It's all GO for plant scientists. Plant Physiol 2005, 138(3): 1268-1279.

69. Telles G, da Silva F: Trimming and clustering sugarcane ESTs. Genet Mol Biol 200I, 24(I-4): I7-23.

70. Ogihara Y, Mochida K, Nemoto Y, Murai K, Yamazaki Y, Shin IT, Kohara Y: Correlated clustering and virtual display of gene expression patterns in the wheat life cycle by large-scale statistical analyses of expressed sequence tags. Plant J 2003, 33(6): $100 \mid-1011$.

7I. Kulterer B, Friedl G, Jandrositz A, Sanchez-Cabo F, Prokesch A, Paar C, Scheideler M, Windhager R, Preisegger KH, Trajanoski Z: Gene expression profiling of human mesenchymal stem cells derived from bone marrow during expansion and osteoblast differentiation. BMC Genomics 2007, 8:70.

72. Hartigan JA: Clustering. Annu Rev Biophys Bioeng 1973, 2:8I-I0I.

73. Sturn A, Quackenbush J, Trajanoski Z: Genesis: cluster analysis of microarray data. Bioinformatics 2002, I 8(I):207-208.

74. Yeung KY, Haynor DR, Ruzzo WL: Validating clustering for gene expression data. Bioinformatics 200I, I7(4):309-3I8.

75. Higuchi R, Fockler C, Dollinger G, Watson R: Kinetic PCR analysis: real-time monitoring of DNA amplification reactions. Biotechnology (N Y) I 993, I I (9): 1026-1030.
Publish with Biomed Central and every scientist can read your work free of charge

"BioMed Central will be the most significant development for disseminating the results of biomedical research in our lifetime. "

Sir Paul Nurse, Cancer Research UK

Your research papers will be:

- available free of charge to the entire biomedical community

- peer reviewed and published immediately upon acceptance

- cited in PubMed and archived on PubMed Central

- yours - you keep the copyright

Submit your manuscript here:

http://www.biomedcentral.com/info/publishing_adv.asp
BioMedcentral 